\title{
Correction to: New clinical manifestation of COVID-19 related Guillain-Barrè syndrome highly responsive to intravenous immunoglobulins: two Italian cases
}

\author{
Andrea Assini $^{1} \cdot$ Luana Benedetti $^{2} \cdot$ Silvia Di Maio $^{3} \cdot$ Erika Schirinzi $^{1,4} \cdot$ Massimo Del Sette $^{1}$ \\ Published online: 8 June 2020 \\ (C) Fondazione Società Italiana di Neurologia 2020
}

Correction to: Neurological Sciences (2020)

https://doi.org/10.1007/s10072-020-04484-5

The above article was published online with inverted given and family names. The correct presentation has been corrected above.

The original article has been corrected.

The online version of the original article can be found at https://doi.org/ 10.1007/s10072-020-04484-5

Massimo Del Sette

massimo.del.sette@galliera.it

1 Neurology Unit, Galliera Hospital, Via Mura delle Cappuccine 14, 16128 Genoa, Italy

2 Department of Neuroscience, Rehabilitation, Ophthalmology, Genetics, Maternal and Child Health (DINOGMI), University of Genova and IRCCS, Policlinico San Martino, Genoa, Italy

3 Intensive Care Unit, Galliera Hospital, Genoa, Italy

4 Neurological Clinic, Department of Clinical and Experimental Medicine, University of Pisa, Pisa, Italy 